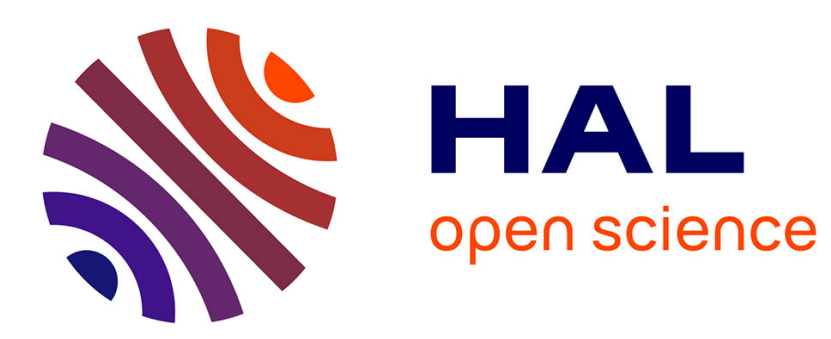

\title{
Workplace Respiratory Protection Factors during Asbestos Removal Operations
}

Sandrine Chazelet, Pascal Wild, Eric Silvente, Céline Eypert-Blaison

\section{To cite this version:}

Sandrine Chazelet, Pascal Wild, Eric Silvente, Céline Eypert-Blaison. Workplace Respiratory Protection Factors during Asbestos Removal Operations. Annals of Work Exposures and Health, 2018, 62 (5), pp.613 - 621. 10.1093/annweh/wxy013 . hal-01845617

\section{HAL Id: hal-01845617 https://hal.science/hal-01845617}

Submitted on $20 \mathrm{Jul} 2018$

HAL is a multi-disciplinary open access archive for the deposit and dissemination of scientific research documents, whether they are published or not. The documents may come from teaching and research institutions in France or abroad, or from public or private research centers.
L'archive ouverte pluridisciplinaire HAL, est destinée au dépôt et à la diffusion de documents scientifiques de niveau recherche, publiés ou non, émanant des établissements d'enseignement et de recherche français ou étrangers, des laboratoires publics ou privés. 


\title{
WORKPLACE RESPIRATORY PROTECTION FACTORS DURING ASBESTOS REMOVAL OPERATIONS \\ S. Chazelet ${ }^{1 *}$, P. Wild ${ }^{2}$, E. Silvente ${ }^{1}$, C. Eypert-Blaison ${ }^{3}$
}

${ }^{1}$ Department of Process Engineering, Institut National de Recherche et de Sécurité, Rue du Morvan, CS 60027, Vandoeuvre-les-Nancy, France; ${ }^{2}$ Scientific Management, Institut National de Recherche et de Sécurité (INRS), Rue du Morvan, CS 60027, Vandoeuvre-lesNancy, France $;{ }^{3}$ Department of Metrology of Pollutants, Institut National de Recherche et de Sécurité (INRS), Rue du Morvan, CS 60027, Vandoeuvre-les-Nancy, France *Author to whom correspondence should be addressed. E-mail: sandrine.chazelet@inrs.fr

\begin{abstract}
Numerous changes have been made to the French labour regulations in recent years relating to the prevention of risks of exposure to asbestos fibres for operators removing asbestoscontaining materials. These changes refer to the method used to count fibres, the collective and personal protective devices to be used on these worksites, and the occupational exposure limit value, which was reduced to $10 \mathrm{f} / \mathrm{L}$ on 2 July 2015 . In this context, this study assessed the level of respiratory protection afforded by supplied-air respirators and powered air purifying respirators by monitoring exposure for several operators on nine worksites. The levels of dustiness measured in personal samples taken outside masks showed significant evidence of potential exposure during removal of asbestos-containing plaster or sprayed asbestos, and when using abrasive blasting to treat asbestos-containing materials. For these tasks outside concentration regularly exceeds $25000 \mathrm{f} / \mathrm{L}$. Measurements inside masks were generally low, under $10 \mathrm{f} / \mathrm{L}$, except in some situations involving the removal of asbestoscontaining plaster. This partial penetration of fibres inside masks could be due to the high
\end{abstract}


loading linked to this material. The distributions of workplace protection factors obtained for the two types of respiratory protective devices studied were broad, and the 5th percentile values, respectively equal to 236 and 104 for supplied air respirators and powered air purifying respirators. This work highlights once again the need to prioritise collective protection when seeking to prevent asbestos-related risks.

\section{Keywords}

Workplace protection factor, asbestos exposure, supplied air respirator, powered air purifying respirator, respirator testing, respiratory protection

\section{INTRODUCTION}

The French regulations define the collective and personal protective measures that should be implemented during operations to remove asbestos-containing materials. These measures are adapted depending on the expected level of dustiness. In addition to collective protective approaches (confinement of the work area, maintaining the area in a depressurised state, aspiration at source, humidification of the material to be removed, etc.), Respiratory Protective Devices (RPD) may be used in situations resulting in most exposure. RPD include powered air purifying respirators (PAPR), which ensure a minimum flow-rate of $160 \mathrm{~L} / \mathrm{min}$; and supplied-air respirators (SAR), which can meet requirements up to $300 \mathrm{~L} / \mathrm{min}$, both with full facepiece mask.

The recommendations made in the regulations are based on the Assigned Protection Factors (APF) for these two types of RPD. According to EN 529:2005 (2005) the Assigned Protection Factor is the level of protection that can be expected for $95 \%$ of well-trained wearers using properly fitted and functioning respirators. In such conditions, measure of the protection is defined by the Workplace Protection Factor (WPF). The WPF corresponds to the level of 
protection measured on an operator while wearing the RPD in an occupational setting. APF is determined from a distribution of WPF values measured on different operators and workplaces. This distribution generally follows a log-normal law and APF equals the fifth percentile of this distribution. The statistical analysis of the WPF distribution will allow to get an updated APF value for both types of RPD tested.

The APF values currently used were determined following several INRS campaigns performed in the 1990s (Villa, 1994) and are equal to 60 for powered air purifying respirators and 250 for supplied-air respirators. Since these values were determined, the changes to regulatory constraints and technological advances have led to the development of new RPD models, in particular with the development of pressure demand supplied-air respirators and an increase in the air-flow-rates for both powered air purifying respirators and supplied-air respirators. In parallel, new asbestos-containing materials have emerged on worksites which require new techniques for their removal. This is the case, for example, with asbestoscontaining plaster, the removal of which started in the early years of this millennium. In addition, since 2012 the French regulations require personal exposure to asbestos fibres to be measured using Analytical Transmission Electron Microscopy rather than Optical PhaseContrast Microscopy, the technique used previously (Villa, 1994). Finally, since 2 July 2015 the Occupational Exposure Limit (OEL) for asbestos fibres has been reduced from 100 to 10 f/L.

The objective of this study was therefore to determine workplace protection factors for the most protective and most frequently used RPD in the French asbestos removal sector. 


\section{METHODS}

\section{Modified masks}

First, a prototype modified mask had to be developed to allow sampling of asbestos fibres inside the mask. Several RPD models among those used for asbestos removal tasks were selected for the study based on their frequency of use and an expected high level of protection on the basis of their APF. Thus, one positive pressure demand supplied-air respirator (SAR) and two models of powered air purifying respirators (PAPR-1 and PAPR-2) were selected. PAPR-1 is composed of a full face mask and a fan worn at the belt and equipped with two P3 filters. PAPR-2 is composed of a full face mask and the fan is connected to the mask and is equipped with one $\mathrm{P} 3$ filter.

The sampling system used inside masks was developed in the laboratory in collaboration with manufacturers. The location of the sample inside mask was imposed by two constraints:

- the introduction into the mask of a 3-pieces open-face cassette for the sampling of asbestos fibers complying with the recommendations of the standard XP X 43-269 (2012) to guarantee identical sampling conditions between the outside and the inside of the mask, - the development of a system common to all mask models.

In a previous study Chazelet (2016) demonstrated that aerosol sampling through the visor of these different models of SAR and PAPR gave a measurement result identical to that measured at the level of the mouth of the wearer. In the same paper (Chazelet (2016)) measurements of $\mathrm{Co} / \mathrm{Ci}$ on wearers in laboratory showed that respiratory protection was not affected by the introduction of this sampling in the visor provided that the RPDs were used in accordance with the manufacturer's recommendations: fit of the mask checked and supply of sufficient breathing air. In order to guarantee reliable measures, a quantitative fit test on all the wearers included in the study must be carried out. 
As the RPDs have undergone significant changes, its compliance with the European directive 89/686/EEC has had to be verified. Certification tests have ensured this compliance.

\section{Equipping operators}

Full equipment of an operator consisted of two sampling lines for asbestos fibres, one drawing a sample from inside the respirator and one taking a sample from the person's breathing zone outside the respirator (Figure 1).

The outside respirator sampling line included a personal sampling pump (Gilair Plus, Sensidyne), made decontaminable, a PVC tubing, and an antistatic open cartridge $(37 \mathrm{~mm}$, electrically-conducting 3-pieces open-face cassette, SKC Omega Specialty Division) placed in the personal breathing zone of the operator. This setup is in accordance with the recommendations set out in standard XP X 43-269 (2012) and ISO 13794 (1999) for sampling of asbestos fibres, which require a sampling flow-rate of $3 \mathrm{~L} / \mathrm{min}$ and the use of an electrically-conducting 3-pieces open-face cassette (37-mm in diameter and fitted with a buffer and cellulose ester membrane filter (pore size: $45 \mu \mathrm{m}$ )).

The inside respirator sampling line consisted of a second personal sampling pump (Gilair Plus, Sensidyne), made decontaminable, connected to an antistatic sampling cartridge connected in an air-tight manner to the visor of the modified respiratory mask. The same type of membrane as the first sampling line is used. 


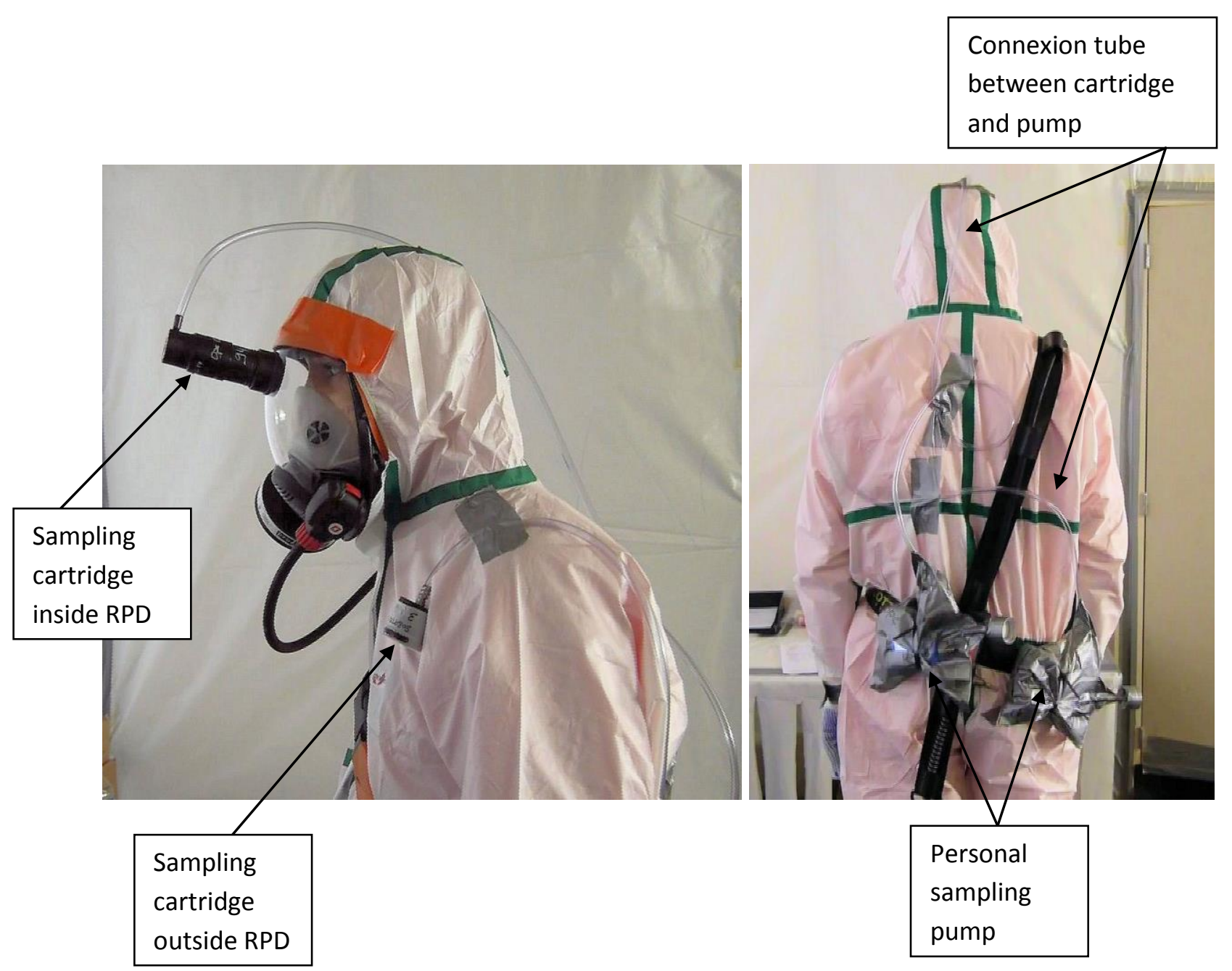

Figure 1: Operator's equipment

\section{Measurement campaigns in work situations}

\section{Description of the worksites}

Asbestos removal operations in France are subjected to strict regulations, in particular in relation to the operators' work rythm. An asbestos removal operator's working day is typically broken down into three phases of work in a confined area, with each phase lasting 90 minutes. These work phases are preceded by suiting-up and followed by decontamination. Between shifts, recovery periods are scheduled.

These worksites were selected to allow analysis of a variety of procedures and expected dustiness levels. On each site, two to three operators fitted with the sampling systems 
illustrated in Figure 1 were monitored over three days. In total on all worksites 25 operators participated in the study.

On the first industrial site (A) the operators removed various asbestos containing materials (surface coatings, sound-proofing, putty) from railway wagons, mainly by pneumatic scraping and sandblasting.

On the industrial sites B and C the operators carried out the removal of sprayed asbestos after watering of the latter. This removal was carried out by scraping with a spatula. The difference between these two workplaces stems from the configuration of the premises, a lot of small areas for the first and a wide area for the second. The organization of work was also different with several operators performing removal and maintenance tasks simultaneously on the first worksite and on the second worksite one operator successively performing the removal and maintenance tasks.

Operations of removal of asbestos containing plaster were followed at worksites $\mathrm{D}$ and $\mathrm{F}$ in identical configuration but with different removal technic: wet scraping for the first one and scraping; remote-controlled machinery and Very High Pressure for the second.

At the worksite $\mathrm{E}$, the operators carried out thermal insulation removal operations.

In the first two workplaces where the PAPRs were evaluated ( $\mathrm{G}$ and $\mathrm{H})$ operators removed adhesive of floor coverings and tiles by sanding and grinding. On the worksite I, the asbestoscement pipes were disassembled.

\section{$\underline{\text { Respirators tested }}$}

The positive pressure demand supplied air respirator (SAR) is tested on worksites A to F, The model of powered air purifying respirator PAPR-1 is evaluated at worksites $\mathrm{G}$ and $\mathrm{H}$ and the model PAPR-2 at worksite I. 


\section{$\underline{\text { Fit test protocol }}$}

During the first day of the campaign, quantitative fit tests were performed on the operators selected for participation in the study. Operators donned their modified masks without air supply and performed a protocol consisting of 8 exercises $(7$ exercises recommended by OSHA (2009) plus one step exercise). Fit factors were monitored with a Portacount (TSI). This test was considered successful, and the operator was included in the measurement campaign, only if the fit factor for each of the test exercises exceeded a threshold of 2000 as recommended by HSE (2012).

\section{Description of the samplings}

The sampling campaign per se was performed on the three days following these tests. Two or three operators were equipped with the sampling lines according to the site. Samples were only collected while the operator worked in the contaminated area. The sampling duration for air inside the mask corresponded to the full time spent in the contaminated area, i.e., around 90 minutes per work shift. Several personal samples were collected outside the RPD in the personal breathing zone of the operator to cover the duration of the period. The sampling duration was adjusted depending on the expected dustiness level for the process being studied; it was generally between 30 minutes and 1 hour, and thus two samples collected during each work shift. The flow-rate for the two personal sampling pumps was set to $3 \mathrm{~L} / \mathrm{min}$, as calibrated using a bubbling flowmeter (Gilibrator) before use. The flow-rate was recorded throughout the sampling period (Gilair + pump, Sensidyne). To ensure that sampling was performed as defined in the protocol, an INRS agent was present in the work area throughout. The numbers of inside and outside samples collected on each worksite are given in table 1. 


\begin{tabular}{|c|c|c|}
\hline Worksite Id. & $\begin{array}{c}\text { Number of outside respirator } \\
\text { samples }\end{array}$ & $\begin{array}{c}\text { Number of inside respirator } \\
\text { samples }\end{array}$ \\
\hline A & 60 & 27 \\
\hline B & 42 & 27 \\
\hline C & 36 & 27 \\
\hline D & 52 & 25 \\
\hline E & 47 & 18 \\
\hline F & 41 & 18 \\
\hline G & 36 & 18 \\
\hline H & 32 & 18 \\
\hline I & 17 & \\
\hline Tab & & \\
\hline
\end{tabular}

Table 1: numbers of asbestos samples realized during the study

\section{End-of-sampling protocol}

A protocol was developed to close the cartridges as soon as the sampling pump was switched off, followed by cleaning of the casing with a wipe and placing them in a closed transport case. The transport case was double-bagged before removing it from the worksite (at the end of the campaign) and subsequently opened under a fume hood in the analysis laboratory. This protocol aimed to limit the risk of contamination of samples as far as possible once sampling cartridges were removed from the work area.

\section{$\underline{\text { Blank measurements }}$}

Five measurements were performed inside respirators on worksites $\mathrm{B}, \mathrm{C}, \mathrm{D}, \mathrm{G}$ and I to serve as field blanks. These measurements were used to determine the limit of detection for the 
analytical method. During these tests, the pumps associated with these samples were not switched on.

\section{Sample analysis}

For samples taken inside the mask, the analytical sensitivity was set to $1 \mathrm{f} / \mathrm{L}$, which is $1 / 10^{\text {th }}$ of the new OEL applicable in France. In order to reach this analytical sensitivity, whole sampling filters for in-mask samples were treated. For the outside sampling filters, fractions of each filter to cover the whole shift, were treated together to return only a single concentration value. The filter fractions treated varied between 1 and 1/8 depending on the overall dustiness level.

Grids were prepared by an indirect method (ISO 13794 (1999)). As usual in France (Kauffer et al., 1996), for this preparation all or part of the sampling filter (or filters) was totally calcinated in an oxygen plasma oven so as to recover only fibres and mineral particles. Hydrochloric acid $(1 \mathrm{~N})$ treatment was used to eliminate any acid-soluble residues. The calcination residues were then re-dispersed and filtered on a pre-carbonated polycarbonate filter (with a pore diameter of $0.2 \mu \mathrm{m}$, according to the French standard NF X43-050). A second carbon deposit was then applied to trap the matter between the two layers. The filter was selectively dissolved to allow sample transfer onto microscopy grids.

Fibres were then observed and analysed by Analytical Transmission Electron Microscopy, based on their morphological, chemical and structural criteria. To comply with the regulatory exposure controls, both WHO-type asbestos fibres (Length $\mathrm{L} \geq 5 \mu \mathrm{m}$, diameter $0.2 \mu \mathrm{m}<\mathrm{D}<$ $3 \mu \mathrm{m}, \mathrm{L} / \mathrm{D} \geq 3)$ and thin fibres $(\mathrm{L} \geq 5 \mu \mathrm{m}, \mathrm{D} \leq 0.2, \mathrm{~L} / \mathrm{D} \geq 3)$ were counted. Counting was stopped when 100 asbestos fibres had been counted or when the analytical sensitivity of the technique was reached. 


\section{Statistical analysis}

All statistical analyses were based on validated pairs of external and internal fibre counts. Fifteen couples of inside/outside measurements were excluded from the analysis for the following reasons: one measurement missing, incorrect use of the RPD (operator wearing a powered air purifying respirator for which the battery indicated an inadequate charge level), or failure to respect the rules for wearing RPD (poorly shaved operator). No data were excluded based on the fibre counts recorded. In total, 132 pairs of external and internal samples were retained to determine the workplace protection factors for supplied-air respirator, and 47 pairs were retained for powered air purifying respirators.

The analyses were performed in two steps: First, descriptive analyses are presented for both outside and inside fibre concentrations for the different RPDs and worksites. Secondly the internal and external fibre counts were modelled using the standard statistical model for count data that is random effect Poisson regression fitted using maximum likelihood (Rabe-Hesketh (2012)). The hypotheses on which this model is based are: The Poisson distribution of asbestos counts, the log-normal distribution of exposure concentrations in workplaces and an assumed log-normal distribution of the WPFs (see supplementary material in online edition). Note that for this model zero counts are data like any other data.

\section{RESULTS}

\section{Outside samples}

The results from analysis of the personal samples taken outside the RPD are expressed as concentrations, Co, for the 25 different operators monitored in the nine companies. For the worksites A to $\mathrm{F}$ where SAR was used the mean geometric outside concentration varies between 79 and $32011 \mathrm{f} / \mathrm{L}$ (Table 2). For the G to I worksites where PAPR were used mean geometric outside concentration varies between 20 to $817 \mathrm{f} / \mathrm{L}$ (Table 2). 


\begin{tabular}{|c|c|c|c|c|c|}
\hline \multirow[t]{2}{*}{ Worksite } & \multirow[t]{2}{*}{ Process } & \multirow[t]{2}{*}{ respirator } & \multicolumn{3}{|c|}{$\operatorname{Co}(\mathrm{f} / \mathrm{L})$} \\
\hline & & & $\begin{array}{c}\text { Geometric } \\
\text { mean }\end{array}$ & $\begin{array}{l}\text { Minimum } \\
\text { value }\end{array}$ & $\begin{array}{c}\text { Maximum } \\
\text { value }\end{array}$ \\
\hline $\mathbf{A}$ & $\begin{array}{c}\text { Removal of surface coatings } \\
\text { (shot peening), sound- } \\
\text { proofing (abrasive blasting) } \\
\text { putty (scraping) }\end{array}$ & SAR & 1075 & 25 & 154941 \\
\hline B & $\begin{array}{c}\text { Removal of sprayed asbestos } \\
\text { (manual scraping) }\end{array}$ & SAR & 32011 & 7606 & 84731 \\
\hline $\mathrm{C}$ & $\begin{array}{c}\text { Removal of sprayed asbestos } \\
\text { (manual scraping) }\end{array}$ & SAR & 8511 & 1828 & 36074 \\
\hline D & $\begin{array}{l}\text { Removal of asbestos- } \\
\text { containing plaster } \\
\text { (pneumatic scraping) }\end{array}$ & SAR & 8448 & 414 & 235838 \\
\hline $\mathbf{E}$ & $\begin{array}{l}\text { Removal of insulation } \\
\text { (manual scraping) }\end{array}$ & SAR & 79 & 6 & 508 \\
\hline $\mathbf{F}$ & \begin{tabular}{|c|} 
Removal of asbestos- \\
containing plaster (scraping; \\
remote-controlled \\
machinery, Very High \\
Pressure) \\
\end{tabular} & $\overline{\text { SAR }}$ & 6604 & 315 & 78076 \\
\hline $\mathbf{G}$ & $\begin{array}{c}\text { Removal of adhesives for } \\
\text { floor coverings and tiles by } \\
\text { chipping and sanding }\end{array}$ & PAPR-1 & 817 & 24 & 8106 \\
\hline $\mathbf{H}$ & $\begin{array}{c}\text { Removal of adhesives for } \\
\text { floor coverings and tiles by } \\
\text { sanding and grinding }\end{array}$ & PAPR-1 & 20 & 3 & 563 \\
\hline I & $\begin{array}{c}\text { Removal of asbestos cement } \\
\text { ducts by breaking - } \\
\text { dismantling }\end{array}$ & PAPR-2 & 57 & 6 & 303 \\
\hline
\end{tabular}

Table 2. Results of outside fibre concentration

The outside concentration values presented in Table 2 illustrate the broad range of exposure encountered on different worksites and during different removal processes (material removed and technique used). Thus, operations to remove asbestos-containing plaster, sprayed asbestos and removing surface coatings by abrasive blasting tend to generate very high concentrations of asbestos fibres. Maximal values of Co for worksites A, B, C, D and F are all over 25000 
f/L which corresponds to the maximum fiber concentration allowed by French regulations.

The outside concentrations measured on worksites G to I where PAPR were used are much lower with geometric mean values all below $1000 \mathrm{f} / \mathrm{L}$.

\section{Inside samples}

\section{$\underline{\text { Limit of detection }}$}

No fibres were detected on any of the five field blank filters. Taking the analytical parameters of the microscope into account, these results were used to determine the Limit of Detection (LoD) for the method which equals $1 \mathrm{f} / \mathrm{L}$. Two classes of outside concentration can then be defined according to Vaughan (2005): low and high exposures when Co is respectively below or above ten times the product between the limit of detection and the Assigned protection Factor.

\section{$\underline{\text { TEMA results }}$}

Table 3 present the results of TEM analysis in simplified terms of the presence (Number of Fiber $\mathrm{Nf} \neq 0$ ) or absence (Number of Fiber $\mathrm{Nf}=0$ ) of asbestos fibers detected on the analyzed fraction of the inside sample.

\begin{tabular}{|c|c|c|c|c|}
\hline $\begin{array}{c}\text { Worksite } \\
\text { Id. }\end{array}$ & respirator & $\begin{array}{c}\text { Total number of } \\
\text { samples where } \mathrm{Nf}=0 \\
\text { (corresponding } \\
\text { fraction) }\end{array}$ & $\begin{array}{c}\text { Total number of } \\
\text { samples where } \mathrm{Nf}=0 \\
\text { and } \\
\text { high exposure } \\
\text { (corresponding } \\
\text { fraction) } \\
\end{array}$ & $\begin{array}{c}\text { Total number of } \\
\text { samples where } \mathrm{Nf}=0 \\
\text { and } \\
\text { low exposure } \\
\text { (corresponding } \\
\text { fraction) }\end{array}$ \\
\hline$\overline{\mathbf{A}}$ & $\begin{array}{l}\text { SAR } \\
\text { A }\end{array}$ & $\begin{array}{c}19 \\
(70.4 \%)\end{array}$ & $\begin{array}{c}3 \\
(11.1 \%)\end{array}$ & $\begin{array}{c}16 \\
(59.3 \%)\end{array}$ \\
\hline B & SAR & $\begin{array}{c}10 \\
(76.9 \%)\end{array}$ & $\begin{array}{c}10 \\
(76.9 \%)\end{array}$ & $\begin{array}{c}0 \\
\text { (NA) }\end{array}$ \\
\hline
\end{tabular}




\begin{tabular}{|c|c|c|c|c|}
\hline C & SAR & $\begin{array}{c}21 \\
(80.8 \%)\end{array}$ & $\begin{array}{c}19 \\
(73.1 \%)\end{array}$ & $\begin{array}{c}2 \\
(7.7 \%)\end{array}$ \\
\hline D & SAR & 13 & 11 & 2 \\
& & $(56.5 \%)$ & $(47.8 \%)$ & $(8.7 \%)$ \\
\hline E & SAR & 19 & 0 & $(76 \%)$ \\
& & $(76 \%)$ & $(\mathrm{NA})$ & $(22.2 \%)$ \\
\hline F & SAR & 10 & 6 & 6 \\
& & $(55.6 \%)$ & $(33.3 \%)$ & $(35.3 \%)$ \\
\hline G & PAPR-1 & 13 & 7 & 16 \\
& & $(76.5 \%)$ & $(41.2 \%)$ & $(88.9 \%)$ \\
\hline H & PAPR-1 & 15 & 0 & 15 \\
& & $(88.2 \%)$ & $(\mathrm{NA})$ & $(88.2 \%)$ \\
\hline I & PAPR-2 & 15 & 0 & $(\mathrm{NA})$ \\
& & $(88.2 \%)$ & & \\
\hline
\end{tabular}

Table 3: Results of Analytical Transmission Electron Microscopy analysis of samples

taken inside respirators

Results show that in the case of the asbestos containing plaster removal process (worksites D and F) direct exposures to asbestos fibers inside respirators are the most numerous with a lowest proportion of samples with no fiber detected in the mask. Table 3 shows that even for low exposure, some fibers were detected on the inside mask samples. Moreover it was observed that fibres can penetrate inside respirators whatever the worksite, the task, the subject, or the work period.

\section{Distribution of workplace protection factors}

Plotting the concentration measured inside the mask, $\mathrm{Ci}$, against the concentration measured outside the mask, Co, shows that no obvious relationship links both concentrations (Figure 2). 
Thus, the workplace protection factor is very variable from one worksite to another and even within the same site.

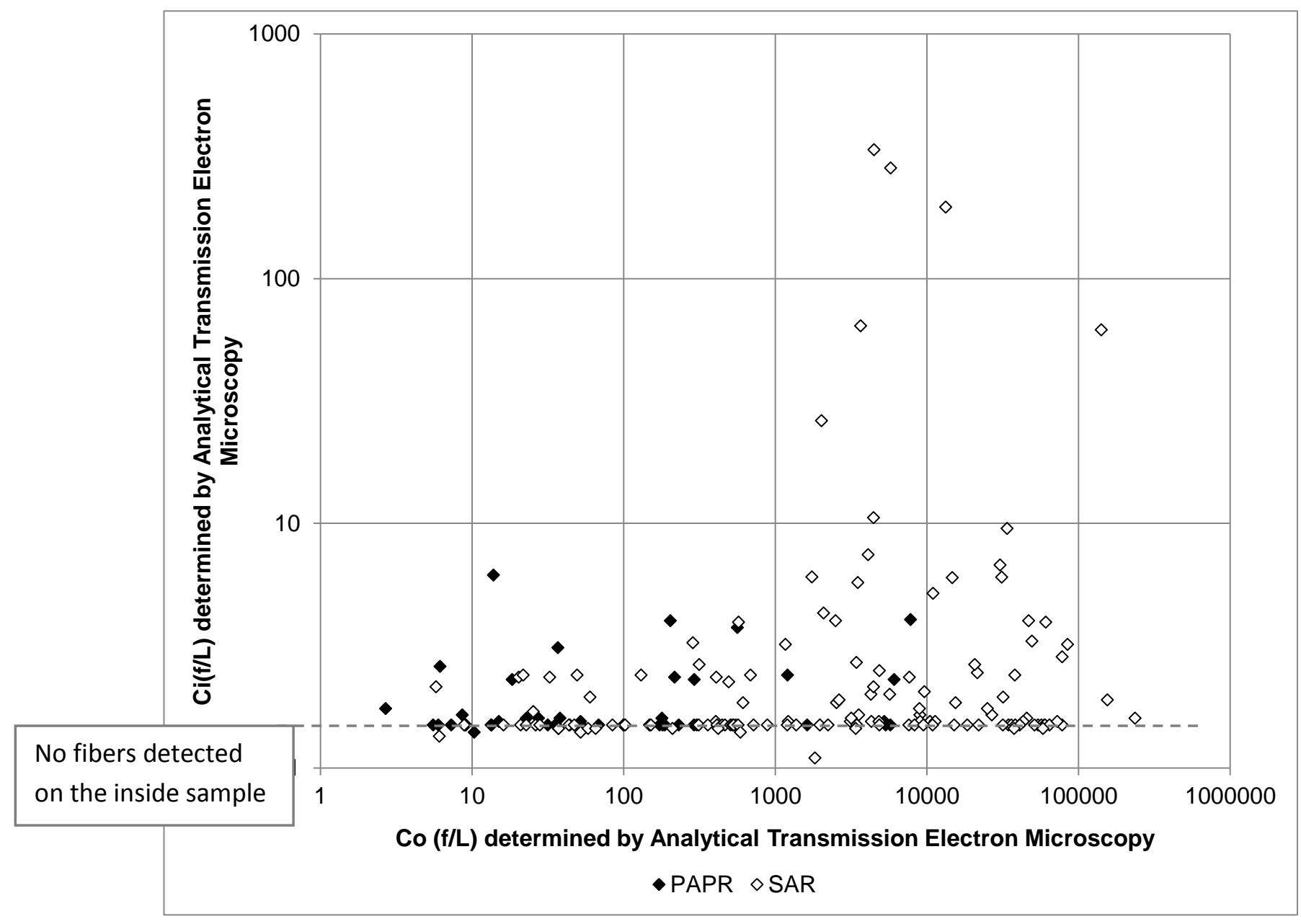

Figure 2: Raw data from Analytical Transmission Electron Microscopy analyses of concentrations measured outside (Co) and inside (Ci) RPD masks (179 pairs)

Results reveal first that in 135 cases on 179 presented on Figure 2, no asbestos fibers are detected on the inside sampling. Secondly in 7 cases on 179 the penetration of asbestos fibers inside the mask is such that $\mathrm{Ci}$ exceeded the $10 \mathrm{f} / \mathrm{L}$ limit value during the work shift. These high values of $\mathrm{Ci}$ are measured for outside dust concentrations greater than $2000 \mathrm{f} / \mathrm{L}$. Moreover all of these high asbestos exposures inside RPD involved worksites where operators 
were equipped with supplied air respirators and engaged in removing asbestos-containing plaster. Table 1 showed that very high level of Co values were obtained during this removal process.

In the case of powered air purifying respirators, which are used on much less dusty sites than supplied air respirators, $\mathrm{Ci}$ values never exceeded $10 \mathrm{f} / \mathrm{L}$.

A comparison of Workplace Protection Factors obtained for each model of PAPR under similar outside dust concentration conditions (workplaces $\mathrm{H}$ and I) led to the conclusion that no significant difference between the two distributions was found. All the measurements carried out on the two models of PAPR have therefore been treated jointly to give only one distribution of WPF for this type of RPD.

Statistical analysis of the data described in the Method section provided a distribution of the workplace protection factors for the two types of RPD studied. The fifth percentile of these distributions equal 236 and 104 respectively for SAR and PAPR (Table 4).

\begin{tabular}{|c|c|c|}
\hline RPD type & SAR & PAPR \\
\hline Number of values analysed & 132 & 47 \\
\hline Geometric mean & 8982 & 886 \\
{$[95 \%$ confidence interval $]$} & {$[5411 ; 14909]$} & {$[420 ; 1871]$} \\
\hline Geometric standard & 9.15 & 3.69 \\
deviation & {$[6.65 ; 13.3]$} & {$[2.62 ; 5.86]$} \\
\hline $\mathbf{5}^{\text {th }}$ percentile for the & & 104 \\
distribution & 236 & \\
\hline
\end{tabular}

Table 4: Characteristics of the distribution of workplace protection factors 


\section{DISCUSSION}

The objective of this study was to determine the workplace protection factors for two types of RPD used on asbestos removal worksites: pressure demand supplied air respirator and powered air purifying respirator. Measurements were performed during asbestos removal, examining the processes likely to lead to the highest emissions of asbestos fibres. Worksites where Sprayed asbestos removal and asbestos containing plaster removal were performed were then selected to evaluate the WPF of the SAR respirator. Worksites of removal of tile and floor tile adhesives, were selected to evaluate WPFs of the PAPRs. Inside and outside respirator samples were carried out on 25 operators on 9 worksites and were analysed by Analytical Transmission Electron Microscopy to obtain workplace protection factors.

Inside respirator samples do not contain asbestos fibers in $75 \%$ of cases on all sites. But in $4 \%$ of cases, the concentration of asbestos fibers inside the masks is higher than the occupational exposure limit value of $10 \mathrm{f} / \mathrm{L}$. These high values of $\mathrm{Ci}$ were all measured inside air-supplied respirators worn by operators performing asbestos containing plaster removal tasks and at outside asbestos concentrations above $2500 \mathrm{f} / \mathrm{L}$. For the PAPRs, the two models studied have similar WPF distributions. A statistical treatment of the Co and Ci data allowed the determination of two WPF distributions for each type of respirator. The 5th percentiles of these distributions were equal to 104 for PAPR and to 236 for SAR.

Few studies exist in the literature to report WPF of SAR or PAPR respirators. The work of Villa (1994) and Howie (1996) are the only ones that provide WPF values for different models of PAPR measured during asbestos removal operations at different sites. Villa (1994) describes highly variable WPFs between 140 and more than 10000 for different operators performing the same removal task. The work of Howie (1996), which has many more measurements than those of Villa (1994), shows that out of 179 Co / Ci ratios, 57 are unquantifiable due to a $\mathrm{Ci}$ below the limit of detection. They also show that in $90 \%$ of the 
cases the mask internal concentrations are below the limit value. In addition, this article concludes that there is no significant difference between the WPF distributions obtained on the different PAPR models. Our findings are consistent with this work, which at that time led to a proposal for an APF for PAPRs of 40.

Campaigns to measure protective factors on PAPRs against other pollutants (Myers (1983), Myers (1984), Lenhart (1984)) came to the same conclusions from a WPF distribution of logtype normal and with a 5th percentile value less than 50. To explain the WPF differences measured during the Myers campaign, the differences in carrier behavior and facial leakage were discussed.

Two measurement campaigns focused on the performance of hood style supplied air respirators (Nelson (2001), Janssen (2008)), both of whom concluded high WPF for this type of APR during sanding and painting operations. . Pollutant detection was done by detection of chemical species including Strontium in both articles. Nelson (2001), who reports the most data, indicates that in sanding operations $50 \%$ of intakes are below the detection limit of strontium compared with $100 \%$ in paint operations. Their authors offer APFs over 1000 for this APR. There is no work on the WPF's pressure demand supplied air respirator with full facemask.

The low values of WPF obtained, in comparison with those of Nelson and Janssen, can be explained by the use of this SAR model in more restrictive conditions: site configuration (multi-storey work on sites B, D, E and F), use of scaffolding (sites B, C, D, F) .These posture constraints and these efforts can lead to a penetration of fibers in the mask, as evoked by Howie (1993).

When $\mathrm{Ci}$ is less than the detection limit of the analytical method adapted to the pollutant, the works cited above all propose a calculation of WPF equal to Co divided by the limit of 
detection, except Howie which considers that in this case WPF> FPN. One major feature of the data of the present paper is that a majority of the within mask fibre counts were zero. Thus no value for a WPF can be obtained from any such data point (pair of counts). However excluding these data was not an option, as this would have led to a serious bias by selecting only the worst situations in terms of presence of within mask fibres. In order to cope with these data we relied on a statistical model fitted using maximum likelihood that allows incorporating all the data including those with zero within-mask fibre counts. This model is based on three hypotheses which we spelled out in the appendix and which are standard in the field of industrial hygiene.

The numerical values of the $5^{\text {th }}$ percentile of each WPF distributions obtained (236 for SAR and 104 for PAPR) are of the same order of magnitude as those used up to now in the French regulations (250 for SAR and 60 for PAPR) (Villa, 1994). However the level of operator training has increased considerably since the 1990s, as well as the level of collective protective measures implemented on worksites. Moreover the RPD assessed in this study present more protective characteristics than the RPD assessed in the 1990s. As a matter of fact the supplied-air RPD used was equipped with a pressure demand valve which did not exist at that time, and the powered air purifying respirators delivered flow rates greater than 160 L/minute. These factors should have led to higher workplace protection factors than those measured in the 1990s. But, today, new asbestos-containing materials, such as asbestoscontaining plaster, are being removed, in some cases through the application of new, more aggressive procedures such as very high pressure. These new asbestos removal situations were linked to the highest risks of exposure to asbestos fibres. This result confirms those presented by Randauceanu in 2008 (Randauceanu, 2008) in the form of a task-exposure matrix. 
These results remind us of the limitations of using personal protective equipment as these devices alone may not guarantee optimal worker protection. Development of protective measures should today focus on the reduction of dustiness in the work area as far as possible, though the development of aspiration at source, work on humidified materials, or even mechanisation when these measures prove insufficient.

\section{Acknowledgments}

The authors would like to thank the INRS teams who participated in the measurement campaigns and the one who carried out all the microscopic analyzes.

\section{Declaration for publication}

Funding for this project was entirely based on the core funding of the Institut National de Recherche et Sécurité (INRS) which is the sole employer of the authors. The authors declare no conflict of interest relating to the material presented in this Article. Its contents, including any opinions and/or conclusions expressed, are solely those of the authors.

\section{SUPPLEMENTARY DATA}

Supplementary data can be found at http://annhyg.oxfordjournals.org/.

\section{REFERENCES}

Chazelet S., Silvente E., Eypert-Blaison C., Belut E. (2016) Asbestos Fibre Sampling through a Facepiece Visor to Measure Workplace Protection Factor. Journal of the International Society for Respiratory Protection; 33, 2: 21-35.

Association Française de NORmalisation (AFNOR). (1998). NF EN 136:1998. Respiratory protective devices - Full face masks - Requirements, testing, Marking. La Plaine SaintDenis, France. 
Association Française de NORmalisation (AFNOR). (2005). NF EN 529:2005. Respiratory protective devices - Recommendations for selection, use, care and maintenance — Guidance document. La Plaine Saint-Denis, France.

Association Française de NORmalisation (AFNOR). (2005). NF EN ISO 8996:2005. Ergonomics of the thermal environment - Determination of metabolic rate. La Plaine SaintDenis, France.

Health and Safety Executive (2012) Fit testing of respiratory protective equipment facepieces. HSE OC 282/28.

Howie R.M., Johnstone J.B.G., Weston P., Aitken R.J., Groat S. (1996) Workplace effectiveness of respiratory protective equipment for asbestos removal work. HSE Contract Research Report nº 112/1996.

Institut National de Recherche et de Sécurité (1998) Occupational exposure of workers employed in asbestos removal - results on 15 removal sites. Cahiers de notes documenatires Hygiène et sécurité du travail ; 173 ; 389-394.

International Standardization Organisation (1999). ISO $13794: 1999$. Ambient air. Determination of asbestos fibres. Indirect-transfer transmission electron microscopy procedure. Geneva: International Standardization Organisation.

Janssen L., Bidweel J., Cuta K., Nelson T.(2008) Workplace performance of a hood-style supplied -air respirator. J. Occup. And Envir. Hyg.; 5 : 438-443.

Kauffer E, Billon-Galland MA, Vigneron JC et al. (1996) Effects of preparation methods of airborne concentrations of asbestos fibres by transmission electron microscopy. Ann. Occup. Hyg.; 40: 321-30.

Myers W.R., Peach M.J., Allender J. (1984) Workplace protection factor measurements on powered air-purifying respirators at a secondary lead smelter - test protocol. Am. Indus. Hyg. 
Assoc. J.; 45, 4: 236-241.

Nelson T., Wheeler T., Mustard T.(2001) Workplace protection factors - Supplied air hood. Am. Ind. Hyg. Assoc.; 62 : 96-100.

Occupational Safety and HealthAdministration, U.S. Department of Labor (2009) Assigned Protection Factors for the Revised Respiratory Protection Standard, OSHA 3352-02.

Radauceanu A., Chouanière D., Wild P., Héry M., Créau Y.(2008) Assessment of asbestos exposure in asbestos removal operations : Proposal of a task exposure matrix. Archives des maladies professionnelles et de l'Environnement; 69: 586-592.

Rabe-Hesketh S., Skrondal A. (2012) Multilevel and Longitudinal Modeling Using Stata Volume II: Categorical responses, Counts and Survival, Third edition, Stata Press Publication, Texas. ISBN-13: 978-1-59718-108-2.

Riala R., Riipinen H. (1998) Respirator and high efficiency particulate air filtration unit performance in asbestos abatement. Appl. Occup. and Environ. Hyg.; 13, 1: 32 - 40.

Vaughan N., Rajan-Sithamparanadarajah B. (2005) Meaningful Workplace Protection Factor Measurement: Experimental protocols and data Treatment. Ann. Occup. Hyg.; 7: 549-561.

Villa M., Hubert G., Lima S., Kauffer E., Hery M. (1994) Occupational Exposure During Asbestos removal Operations. Journal of the International Society for Respiratory Protection; $12,4: 7-14$.

Association Française de NORmalisation (AFNOR). (2012). XP X 43-269:2012. Air quality - Workplace atmospheres — Sampling on membrane filters for the determination of the fibre number concentration by microscopic techniques: phase contrast optical microscopy, scanning electron microscopy analysis and transmission electron microscopy analysis counting by phase contrast optical microscopy. La Plaine Saint-Denis, France. 